\title{
Exposure Effects in Person Perception: Familiarity, Similarity, and Attraction
}

\author{
RichaRd L. MORELAND \\ University of Pittsburgh
}

AND

RoBERT B. ZAJONC

University of Michigan

Received December 3, 1980

\begin{abstract}
Two experiments explored the relationship between familiarity, similarity, and attraction. In the first experiment, subjects viewed photographs of faces at various exposure frequencies and then rated them for likeableness and similarity. Familiar people were regarded by the subjects as both more likeable and more similar to themselves. The effects of familiarity on perceived similarity were primarily mediated by changes in attraction, although some evidence of a direct link between familiarity and perceived similarity was also found. In the second experiment, subjects viewed the same stimuli at a single exposure frequency, and received bogus information regarding the similarity of the people shown therein. Subsequent ratings of likeableness and perceived familiarity revealed that people who seemed similar to the subjects were regarded as both more likeable and more familiar. The effects of similarity on perceived familiarity were almost entirely mediated by changes in attraction. Some of the theoretical implications of these findings are discussed.
\end{abstract}

Research on the mere exposure phenomenon has focused most often on the attitudinal effects of repeated exposure to nonsocial stimuli (cf. Harrison, 1977). There is some evidence, however, that exposure effects can occur in person perception as well. Several experiments have shown

The research reported here was supported by National Science Foundation Grant GS35495. The authors thank Don Meyer and Paul D. Sweeney for their help with the data analyses, and Donn Byrne, Joe Grush, Al Harrison and Margaret Matlin for their comments on an earlier version of the manuscript. Requests for reprints should be sent to Richard L. Moreland, Department of Psychology, University of Pittsburgh, Pittsburgh, PA 15260. 
that mere exposure to others can produce feelings of attraction. Some of these experiments involved manipulations of the amount of contact between subjects in a laboratory setting (Brockner \& Swap, 1976; Saegert, Swap, \& Zajonc, 1973; Swap, 1977). The results showed that interpersonal attraction varied positively with the frequency of prior encounters, even when those encounters did not entail social interaction. Several experiments involving the mere repeated exposure of other social stimuli, such as names (Harrison, Tutone, \& McFadgen, 1971; Stang, Note 1) and photographs (Hamm, Baum, \& Nikels, 1975; Wilson \& Nakajo, 1965; Zajonc, Markus, \& Wilson, 1974; Diamond \& Miller, Note 2), have also been performed. In each case, repeated exposure was found to enhance subjects' feelings of attraction toward the people represented in the stimulus materials.

Clearly, mere exposure can influence attraction under a variety of conditions. People who are encountered more frequently seem to elicit greater feelings of attraction from us, even though little or no social interaction has actually taken place. It is possible, however, that mere exposure has another important effect on person perception as well. In particular, mere exposure may increase the perceived similarity of others to ourselves.

There are at least two ways in which mere exposure could alter our beliefs about the similarity of others. First, repeated exposure could have a direct effect on perceived similarity, regardless of any corresponding changes in attraction. We often assume that the people we meet share at least some of our own attitudes, values, and beliefs (e.g., Adams-Webber, 1977; Benjafield \& Adams-Webber, 1975; Blanchard, 1966; Cloyd, 1977; Messé \& Sivacek, 1979; Ross, Greene, \& House, 1977). This initial assumption may subsequently affect both the acquisition and processing of any new information that we acquire about those individuals (cf. Snyder, 1981; Taylor \& Crocker, 1981; Wyer \& Srull, 1980). For example, information that seems consistent with our assumption of similarity may be sought out or attended to more closely, encoded more efficiently, perceived as more valid, and remembered better later on. Also, inconsistent information may sometimes be distorted, so that it seems more consistent with our preconceptions. Even if no real interaction occurred, every encounter with the people involved would thus provide further "evidence" that our initial assumption of interpersonal similarity was indeed correct. In the absence of any clear evidence of dissimilarity, therefore, repeated exposure to other people could produce a growing belief that they are similar to us in many ways.

A second possibility is that repeated exposure has an indirect effect on the perceived similarity of others by virtue of our general need for consistency and "balance" (Heider, 1958). Through a variety of processes, such as the reduction of response competition (Harrison, 1968; 
Matlin, 1970), repeated exposure to other people generally produces greater liking for them. Several studies have shown that liking for others often leads to the belief that they are similar to ourselves in their attitudes and values (e.g., Byrne \& Blaylock, 1963; Davitz, 1955; Fiedler, Warrington, \& Blaisdell, 1952; Moss, Byrne, Baskett, \& Sachs, 1975; Precker, 1953), perhaps because it seems inconsistent to feel attracted toward someone who disagrees with us. This suggests that mere exposure could affect the perceived similarity of others indirectly through the mediating influence of attraction. By improving our attitudes toward other people, repeated exposure may thus enhance their perceived similarity as well.

Clearly, there are good a priori reasons to expect that mere exposure to other people will increase their perceived similarity to ourselves. This hypothesis has not been tested directly thus far, but there is some suggestive evidence that it may be correct. Several studies have shown that social interaction, especially of a cooperative and friendly nature, can lead to perceptions of interpersonal similarity (e.g., Arkin \& Burger, 1980; Backman \& Secord, 1962; Bieri, 1953; Curry \& Kenny, 1974; Insko \& Wilson, 1977; Rosenbaum, 1959). Bieri (1953), for example, asked pairs of unacquainted college students to evaluate a psychology course in which they were enrolled and to make some preliminary plans for an upcoming summer vacation. Within each pairing, the subjects were either allowed to interact with one another as they performed these tasks, or they were required to perform them on their own. The subjects' predictions about their partners' responses to the Rosenzweig Picture Frustration Test were obtained at both the beginning and the end of the experiment. By comparing these predictions with each subject's own test responses, a measure of perceived similarity was obtained. The results revealed that all of the subjects regarded their partners as more similar to themselves at the end of the experiment than they did at the beginning. This effect was strongest, however, among those subjects who interacted with one another while performing the tasks.

Insofar as social interaction necessarily involves some interpersonal contact, findings like these are at least consistent with the prediction that repeated exposure to others increases their perceived personal similarity. It is not yet known, however, whether mere exposure to other people, in the absence of any real social interaction with them, is a sufficient condition for the enhancement of their perceived similarity to ourselves. The following experiment was designed to provide a more direct test of that hypothesis.

\section{EXPERIMENT 1}

The subjects in the first experiment were shown a photograph of a male college student once a week for 4 weeks. One-half of the subjects 
saw the same photograph each week (repeated exposure), while the other half saw a different photograph each week (single exposure). Data regarding the subjects' attitudes toward the people shown in the photographs, and their beliefs about the degree to which those individuals shared their own values, were collected at each experimental session. It was predicted that repeated exposure to the same stimulus photograph would increase the attractiveness and perceived similarity of the person shown therein.

\begin{abstract}
Method
Subjects

Sixty-four men and 64 women took part in the experiment. All of the subjects were undergraduate students in introductory psychology classes at the University of Michigan. Participation in the experiment enabled the subjects to complete a course requirement.
\end{abstract}

\title{
Stimuli and Materials
}

The stimuli were 4 black-and-white photographs $(9 \times 9 \mathrm{~cm})$ taken from a recent college yearbook. Each photograph depicted a different male undergraduate student. Pretesting indicated that these 4 stimuli did not differ from one another in their initial levels of attractiveness and perceived similarity, or in their distinctiveness and memorability.

In order to evaluate the degree to which the subjects regarded the people shown in these stimuli as personally similar, a modified version of Shorr's Test of Value Activities (Shorr, 1953) was used. This test assesses the intensity with which people hold theoretical, social, aesthetic, and economic-political values. In the original form of the test, respondents are asked to indicate whether or not they would enjoy engaging in each of 80 specified activities. Each activity corresponds to one of the 4 value categories, so that each category is represented by 20 different activities. Enjoyment of a particular activity is presumed to indicate the strength of the individual's commitment to the corresponding value. A special feature of the test is its use of paired items, 10 for each value category. Every item is equivalent psychometrically to another particular item within the test, in the sense that both reflect an equally strong commitment by the individual to the same type of values.

For the purposes of this research, the test was modified in several ways. First, a Likerttype response format was adopted, so that the subjects rated each activity on a 7-point LIKE-DISLIKE scale. Secondly, the test was divided into 2 smaller scales (hereafter referred to as Forms A and B) by separating all of the paired items from one another. The 2 resulting scales each contained 40 randomly ordered items that provided comparable measures of the samc value categories. Form B was further divided at random into 4 subscales, each containing 10 items. Form A was not subdivided in this manner. Finally, the subjects' feelings of attraction toward the men shown in the stimuli were assessed by means of a final 7-point LIKE-DISLIKE rating scale, which was included at the bottom of each of the Form B subscales.

All of these materials were pretested using procedures identical to those that were later employed in the experiment. The purpose of this pretesting was to ensure that the measures of perceived similarity and interpersonal attraction possessed adequate face validity and reliability. Subjects who participated in the pretesting sessions $(N=64)$ had no difficulty in either understanding or performing their required tasks, and reported that the materials were both believable and involving. Based on their responses, the estimated reliabilities for perceived similarity and attraction were .85 and .90 , respectively. 


\section{Procedure}

The subjects were told that they would be participating in a study of "college students' attitudes, values, and beliefs," and that the research would begin with an examination of their own thoughts and opinions. All of the subjects were then given Form A of the values test and asked to rate on a 7-point LIKE-DISLIKE scale how much they would like to engage in each of the 40 specified activities. No time limitations were placed on the completion of this task, but most of the subjects were able to finish it within about $10 \mathrm{~min}$.

After a week had passed, the subjects were contacted for the second phase of the experiment. They were told that the research would now focus on their "ability to form an accurate impression of the attitudes, values, and beliefs of other college students." Each was then given an envelope, bearing his/her name, that contained 1 of the photographs and 1 of the 4 subscales obtained from Form B of the values test. The subjects were first asked to look at the photograph for a few minutes, and then to try to form some general impressions about the individual shown in it. Afterwards, they utilized those initial impressions to guess, on a series of 7-point LIKE-DISLIKE scales, how much that person might like to engage in each of the 10 activities listed on the Form $B$ subscale. The subjects also guessed, on a final 7-point LIKE-DISLIKE scale, how much they might like the person shown in the photograph if they were to meet him in the near future. The subjects were not permitted to communicate with one another while performing these tasks, and were asked to refrain from discussing the experiment with one another after leaving the room. As before, no time limitations were placed on the subjects, but most of them were able to finish the tasks within about $15 \mathrm{~min}$.

The second phase of the experiment extended over a period of 4 weeks, with subjects performing the same 2 tasks at every weekly experimental session. Each subject received a separate envelope on each occasion. The contents of the envelopes were manipulated systematically by the experimenter. All of the subjects received a different subscale from Form B of the values test in each week's envelope, and an equal number of men and women received each of the 4 subscales at each experimental session. Moreover, the order in which those subscales were distributed was counterbalanced across subjects of the same sex, so that the same number of men and women received their Form $B$ subscales in each of the 4 possible distribution orders generated by a Latin square.

The most important manipulation of the materials, however, involved the photographs. Thirty-two subjects of each sex were chosen randomly to receive the same stimulus photograph in each of their weekly envelopes, while the other half of the sample received a different stimulus photograph in their envelope each week. Overall, an equal number of men and women received each of the 4 photographs at each experimental session. For those subjects who were given a different stimulus each week, a second counterbalancing scheme ensured that the same number of men and women received the photographs in each of the 4 possible distribution orders. The procedures used to determine which Form B subscale and stimulus photograph a subject would receive during a particular experimental session, however, were completely independent.

As soon as the experiment was completed, the subjects were asked to make some guesses about the purpose of the research. None of them was able to identify correctly the experimental hypotheses that were being tested. Finally, the subjects were debriefed, permitted to ask questions about the experiment, and thanked for their participation.

\section{Results}

The data analyses focused on the effects that familiarity had on the perceived similarity and attractiveness of the people shown in the stimulus photographs. Familiarity was defined objectively in terms of the 
actual frequency with which subjects were exposed to the people shown in the stimulus photographs, and not subjectively in terms of how familiar those people seemed to be to the subjects. Frequency of stimulus exposure was determined by the interaction between stimulus set and experimental sessions. Exposure frequencies increased with each experimental session for subjects who always saw the same photograph, but remained constant for subjects who saw a set of 4 different photographs. Systematic changes in the attractiveness and perceived similarity of the people shown in the stimulus photographs were not expected to occur among the latter group of subjects.

Interpersonal attraction was measured directly through the subjects' ratings of how much they would like the people shown in the stimulus photographs if they were to meet them sometime in the future. In order to avoid the possibility of confounding experimental demand characteristics, however, perceived similarity was measured in a more unobtrusive fashion. The subjects' responses on Form A of the values test, which indicated their activity preferences, were compared with their responses on the various Form B subscales, which indicated their guesses about the activity preferences of the people in the photographs. The correspondence between these 2 sets of responses thus provided an indirect measure of whether the subjects regarded those individuals as personally similar.

To assess perceived similarity, a series of 4 correlation coefficients was first calculated for each subject. Each correlation was based on 10 pairs of responses, and represented the degree to which the subject's responses on one of the Form $B$ subscales matched his/her prior responses to the 10 corresponding items on Form A of the values scale. ${ }^{1}$ For the purposes of analysis, all of these correlations were then transformed by means of Fisher's $r$-to- $z$ procedure (cf. Hays, 1963).

The effects of repeated stimulus exposure on attraction and perceived similarity are shown in Fig. 1. There were no differences between the responses of male and female subjects, so the data were averaged across sex. Familiarity seemed to have parallel effects on both dependent measures, and those effects were primarily linear in form; no significant curvilinear trends were observed in the data. Moreover, the results appeared to confirm the hypothesis, since both attraction and perceived similarity were correlated positively with familiarity.

Multifactor repreated measures analyses of variance were planned as

' Other measures of perceived similarity, such as difference scores or indices of profile similarity across value categories, could have been calculated. Pretesting indicated, however, that all of these measures were correlated highly with one another. Simple correlation coefficients were chosen as the major dependent measure because they were easy to interpret, made use of all the subjects' responses, and took into account possible differences in individual response styles (e.g., elevation and variability of activity preferences). 


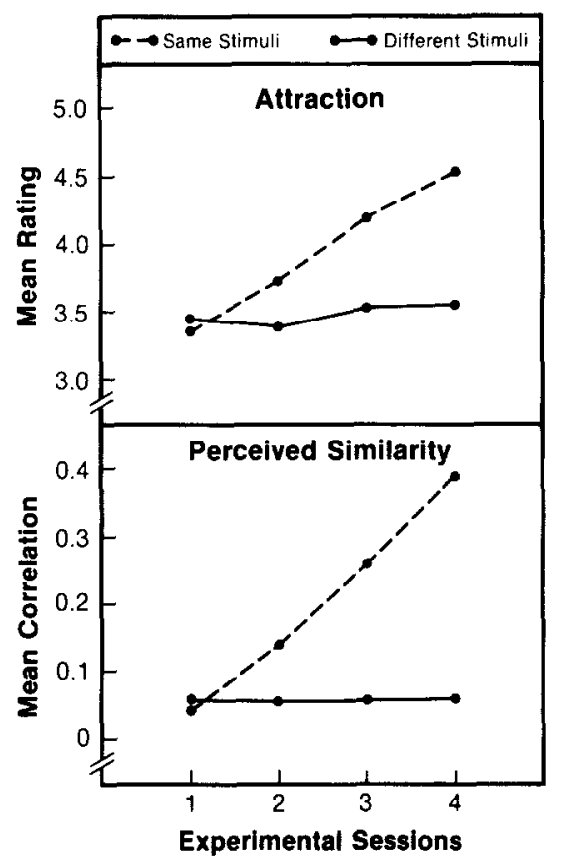

FIG. 1. Effects of familiarity on perceived similarity and attraction,

tests of these effects, but a preliminary examination of the data (cf. Huynh \& Feldt, 1970) revealed that the rather restrictive statistical assumptions associated with such analyses were not well met. An alternative analytical strategy was therefore adopted. Two composite scores were computed for each of the subjects who saw the same stimulus photograph each week. One score represented the linear effects of familiarity on attraction; the other represented the linear effects of familiarity on perceived similarity. Both scores were computed in precisely the same way. First, the 4 weekly responses obtained from each subject were weighted by a series of coefficients $(-3,-1,1,3)$ reflecting a linear trend across the 4 experimental sessions. The 4 weighted responses were then summed to produce a single composite score. These composite scores provided information about both the direction and strength of the linear trend in each dependent measure over time.

Analyses of these composite scores revealed significant exposure effects for both dependent measures. The average composite attraction score for subjects who saw the same stimulus photograph each week $(M=3.97)$ was significantly greater than zero, $t(63)=6.09, p<.01$, and also larger, $t(126)=3.69, p<.01$, than the average score for subjects who saw a different photograph each week $(M=.42){ }^{2}$ The

\footnotetext{
${ }^{2}$ One-tailed tests of significance were used in all analyses, since specific hypotheses were being tested in every case.
} 
latter mean was not significantly different from zero, $t(63)=.60, p>$ .05 . Clearly, familiarity had a strong positive linear effect on the subjects' feelings of attraction toward the people shown in the stimulus photographs.

Similar results were obtained from analyses of the subjects' composite perceived similarity scores. The average score for subjects who saw the same stimulus photograph each week $(M=1.17)$ was again significantly greater than zero, $t(63)=4.38, p<.01$, and also larger, $t(126)=3.51$, $p<.01$, than the average perceived similarity score for subjects who saw a different photograph each week $(M=.01)$. Once again, the latter mean was not significantly different from zero, $t(63)=.06, p>.05$. Apparently, familiarity not only improved the subjects' attitudes toward the people in the stimulus photographs, but also had a strong positive linear effect on their beliefs about how similar those people were to themselves. ${ }^{3}$

Although the results of these initial analyses showed that mere exposure can affect both attraction and perceived similarity, they provided insufficient information about the causal nature of the observed exposure effects. In order to investigate this issue more closely, two regression analyses were performed on the linear composite scores of subjects who saw the same stimulus photograph each week. In the first analysis, the perceived similarity scores $(P S)$ of those subjects were regressed on their attraction scores $(A)$. This regression proved to be significant, $F(1,62)$ $=7.56, p<.01$, with an $R^{2}$ of .11 and a standard error of 2.02. Linear trends in perceived similarity thus appeared to be linked closely to linear trends in attraction. The regression equation generated by the analysis, $\hat{P S}=.63+.13 A$, was particularly interesting, since it provided information regarding the probable pattern of causal relations within the data. Specifically, the additive constant in that equation estimated the strength and direction of any linear effects that familiarity might have had on perceived similarity if there had been no linear effects of familiarity on attraction $(A=0)$. In other words, the constant allowed for a test of

\footnotetext{
${ }^{3}$ We also considered the possibility of boredom or fatigue among subjects who saw the same stimulus photograph each week. These subjects may have abandoned the relatively difficult task of guessing the activity preferences of the person in that photograph, and responded instead on the basis of their own preferences for the activities. If this behavior occurred among enough of the subjects, and became more common as weeks went by, then it could have produced an artifactual relationship between familiarity and perceived similarity.

The available evidence suggested, however, that this was not a serious problem in our research. There were no overt signs of boredom among subjects who saw the same stimulus photograph each week. In fact, several of them commented during debriefing about how "happy" they were to see a "familiar face" each week. Anyone who became bored with the experiment could easily have dropped out, or responded randomly to the questionnaire items on the Form B subscales. No one followed either course of action, as far as we were able to determine.
} 
the hypothesis that the effects of familiarity on perceived similarity were mediated by concomitant changes in attraction. Tests of the constant showed that while it was still significantly larger than zero, $t(62)=1.98$, $p<.05$, it was also smaller, $t(62)=-1.68, p<.05$, than the original mean perceived similarity score $\left(b_{0}=.63\right.$ vs $\left.M=1.17\right){ }^{4}$ In fact, the regression analysis indicated that removing all of the linear trends in attraction would have eliminated more than half of the average linear trend in perceived similarity. All of this suggests that the observed effects of repeated stimulus exposure on perceived similarity would have been reduced greatly, if not eliminated entirely, had there been no corresponding effects of repeated stimulus exposure on attraction.

The possibility that familiarity had some direct effects on perceived similarity made it necessary to consider the alternative hypothesis that the effects of familiarity on attraction were mediated at least partially by concomitant changes in perceived similarity. To test that hypothesis, a second regression analysis was performed in which subjects' attraction scores were regressed on their perceived similarity scores. The regression was, of course, unchanged $\left(R^{2}=.11\right)$, but had a new standard error of 4.96. The regression equation generated by this second analysis, $\hat{A}=$ $3.03+.81 P S$, again provided information regarding the probable pattern of causal relations within the data. In this case, the constant indicated whether perceived similarity mediated the effects of familiarity on attraction. Tests on the constant revealed that while it too was larger than zero, $t(62)=4.28, p<.01$, it was not significantly smaller, $t(62)=$ $-1.33, p>.05$, than the original mean attraction score $\left(b_{0}=3.03\right.$ vs $M=3.97)$. These findings suggest that the observed effects of repeated stimulus exposure on attraction would have changed very little had there been no corresponding effects of familiarity on perceived similarity.

\section{EXPERIMENT 2}

The results of the first experiment revealed that mere exposure can indeed influence both our attitudes and beliefs about other people. Although the psychological processes underlying those changes must be studied more extensively before they can be fully understood, the analyses suggested that the effects of familiarity on perceived similarity were primarily mediated by attraction. As the subjects became objectively more familiar with the people shown in the photographs, they began to regard those individuals as more likeable. This increased attraction led in turn to a growing belief that the people in the photographs were more similar to the subjects as well.

${ }^{4}$ Alternatively, one could test the hypothesis that the observed average perceived similarity score was larger than the constant from the regression equation. This alternative test, which involved a different error term, was also significant, $t(63)=2.01, p<.05$. 
If mere exposure to other people can make them seem more similar to ourselves, then the reverse phenomenon may also occur. That is, people who are similar may sometimes seem familiar to us, especially if they are actually strangers or very recent acquaintances. Naturally, similarity cannot alter the objective familiarity of other people, since that is determined solely by the frequency of our prior encounters with them. It is possible, however, that the perceived familiarity of others might be influenced by their similarity to ourselves, at least under some conditions.

By analogy with the first experiment, there are at least two ways in which similarity could influence our judgments about the familiarity of others. First of all, the degree to which other people are personally similar could have a direct effect on their perceived familiarity, regardless of any corresponding changes in attraction. When we encounter people who are similar to us, we are spontaneously reminded of ourselves and our past experiences. These memories may produce a sort of "halo" effect, in which we regard the people who evoke them as more familiar, especially when we are uncertain about how familiar those individuals actually are. In effect, extensive familiarity with ourselves would enhance the perceived familiarity of others, insofar as they appear to be similar to us in some way.

A second possibility is that similarity has an indirect effect on the degree to which other people seem familiar to us. A number of experiments have shown that we feel attracted toward those who are similar to ourselves (Byrne, Gouaux, Griffitt, Lamberth, Murakawa, Prasad, Prasad, \& Ramirez, 1971; Byrne \& Nelson, 1965; Griffitt, Nelson, \& Littlepage, 1972), perhaps because they provide consensual validation for our own attitudes, values, and beliefs (Byrne \& Clore, 1970). Because we like similar others, memories about our prior interactions with them can become distorted, usually in ways that lead to cognitive consistency (Heider, 1958). In particular, feelings of attraction can enhance the perceived familiarity of other people, causing us to overestimate the frequency with which they have been encountered (cf. Gerard, Green, Hoyt, \& Conolley, 1973; Matlin \& Stang, 1978; Stang, Note 3). This suggests that similarity could indeed affect the perceived familiarity of others through the mediating effects of attraction. People who are personally similar would thus appear to be more familiar to us as well, if only because we have come to like them.

Whether its effects are direct or instead mediated by attraction, the belief that another person is similar to ourselves clearly ought to increase his or her perceived familiarity. Once again, there is no direct evidence in the literature regarding this hypothesis. At least two experiments (McLaughlin, 1970, 1971), however, have investigated the influence of similarity on our ability to recall information about others. Insofar as memorability and familiarity are correlated positively with one another, 
such evidence seems relevant to the issue at hand. In one experiment, McLaughlin (1970) varied the perceived similarity of several stimulus persons and then measured subjects' (a) attraction toward those individuals and (b) ability to recall information about them. The results revealed that similarity not only produced feelings of attraction, but also promoted better recall. In a subsequent experiment, McLaughlin (1971) varied both the likeableness and the perceived similarity of various stimulus persons, and again measured subjects' interpersonal attraction and recall. Likeableness had a significant effect on the subjects' ability to recall information about others, but similarity did not. Recall was best, however, for likeable people who were similar to the subjects, and worst for unlikeable people who were dissimilar to them. The effects of similarity on recall thus appeared to be mediated by attraction.

Findings like these are at least consistent with the hypothesis that similarity can enhance the degree to which other people seem familiar. In order to test that hypothesis more directly, however, a second experiment was performed. The subjects in that experiment were shown a series of stimulus slides, each depicting a different male college student. All of the slides appeared an equal number of times, so that their objective familiarity to the subjects was the same in every case. After viewing the slides, the subjects received information indicating that the values of the individuals they had seen were more or less similar to their own values. Finally, the subjects indicated how much they liked the people shown in the slides, and how familiar those individuals seemed to them to be. It was predicted that people who were more similar to the subjects would also appear to be more attractive and familiar.

\section{Method}

\section{Subjects}

Thirty-two men and 32 women participated in the experiment. All of the subjects were undergraduate students in introductory psychology classes at the University of Michigan. Participation in the experiment allowed the subjects to complete a course requirement.

\section{Stimuli, Apparatus, and Materials}

The stimuli were ten $35-\mathrm{mm}$ black-and-white slides, each portraying a different male undergraduate student. Four of the slides were identical to the 4 stimulus photographs used in the first experiment, while the remaining 6 slides were taken from photographs found in the same college yearbook. A Keystone 1055 projector was used to show the slides, and exposure timing was controlled with a Lafayette 43011-16 electronic shutter.

In order to manipulate the similarity of the people shown in the slides to the subjects, the Shorr Test of Value Activities (cf. Shorr, 1953) was again used. The test was modified in exactly the same way as in the first experiment. Form A of the test was again used to assess the subjects' preferences for various value-related activities, while the $\mathbf{4}$ subscales taken from Form $B$ of the test were used to give the subjects bogus information about the activity preferences of some of the individuals shown in the slides. 


\section{Procedure}

Subjects participated in the experiment in small groups, with each group ranging in size from 3 to 6 persons. The subjects were not allowed to interact with one another during the experiment, since the research focused primarily on their individual reactions to the stimuli. Upon entering the laboratory, the subjects were first seated behind a long, narrow table, so that each person had a clear view of a projection screen placed about $10 \mathrm{ft}$ away. As in the first experiment, the subjects were then told that the research investigated the "attitudes, values, and beliefs of college students," and that the experiment would begin with an examination of their own thoughts and opinions. All of the subjects were then given Form $\mathrm{A}$ of the modified values test, and asked to rate on 7-point LIKE-DISLIKE scales how much they would like to engage in each of the 40 specified activities. No limitations were placed on the amount of time that the subjects had to complete this task, but most of them finished it within about $10 \mathrm{~min}$.

After the subjects had finished describing their own preferences for the various activities, they were told that the experiment would next focus on their "ability to form a clear and accurate impression about other college students." The subjects were first asked to sit quietly and watch a series of slides. The 10 stimulus slides were then shown 10 times each in a random predetermined order that was the same for all subjects. Each slide was shown for $2 \mathrm{sec}$, followed by an interval of $5 \mathrm{sec}$ until the next slide appeared. This phase of the experiment lasted for about $15 \mathrm{~min}$.

While the subjects sat watching the slides, the experimenter passed their completed values tests (Form A) quietly to an assistant in the next room. This assistant was never seen by the subjects, nor was he referred to by the experimenter at any time. His purpose was to provide the subjects with bogus information about the activity preferences of some of the people shown in the slides. This was accomplished through the use of the 4 subscales taken from Form B of the values test, which were filled out by the assistant in ways that were more or less similar to the subjects' prior responses to the corresponding items on Form A.

For each subject, the assistant was provided with a packet containing the 4 Form B subscales stapled together. These 4 subscales were blank, except that the names of the fictitious respondents had already been recorded on them. The same name always appeared on the same Form B subscale across all subjects, but the order of the subscales within the packets was counterbalanced for each sex, so that each subscale appeared in each of the 4 booklet positions (first, second, third, or fourth) an equal number of times for both men and women.

The assistant performed the same tasks for each subject. He began by selecting a booklet of Form B subscales and then matching the activities listed on those subscales with the corresponding activities that the subject had already rated on Form $A$ of the values test. The assistant then took the first subscale and transferred either 2, 4, 6, or 8 of the subject's ratings of the appropriate Form A activities onto the 7-point LIKE-DISLIKE rating scales associated with the Form $B$ activities. The remaining activities on each subscale were given ratings by the assistant that were 2 scale points either above or below the subject's own ratings of the corresponding Form A activities. This procedure was repeated for the other 3 subscales, so that the completed booklet contained 4 sets of ratings that represented 4 different levels of similarity to the subject's own activity preferences. ${ }^{5}$ This manipulation

\footnotetext{
${ }^{5}$ Within each level of similarity, the actual correspondence between the subject's activity preferences and those recorded by the research assistant on the Form B subscales thus varied from one person to another. In order of increasing similarity, the actual correlations between the subjects' activity preferences and those recorded on the values subscales were later found to be $+.13,+.42,+.63$, and +.81 , respectively. Planned comparisons between these average correlations revealed that they indeed represented four distinct levels of similarity between the subjects' own responses and those provided by the assistant.
} 
was also counterbalanced for each sex, so that each of the 4 subscales (and its fictitious respondent) fell into each level of similarity an equal number of times for both men and women.

As soon as the assistant finished filling out booklets for all of the subjects at a particular experimental session, he passed them along quietly to the experimenter, who had remained with the subjects in the projection room all along. Again, care was taken to ensure that the subjects were unaware of the assistant's role in the research.

When the subjects had finished viewing the slides, they were each given the appropriate booklet of Form $B$ subscales, and a single page of response measures containing 4 pairs of 7-point LIKE-DISLIKE and FAMILIAR-UNFAMILIAR rating scales. The subjects were told that 4 of the people who had appeared in the previous series of slides would be shown again, thus providing an opportunity to form a "better" impression of them. The subjects were led to believe that they would be aided in this task by the booklets, which purportedly contained information about the activity preferences of the people appearing in those 4 slides. The subjects were instructed to look first at the person shown on the screen, and then to read about his preferences for the 10 activities described on the appropriate page of the booklet. Once a "clear" impression of the individual had formed, the subjects were told that they should guess (on a LIKE-DISLIKE scale) how much they might like that person if they were to meet him in the near future, and then rate (on a FAMILIAR-UNFAMILIAR scale) how familiar that person seemed to them. Subjects were also asked to estimate how many times each person's face had appeared during the earlier exposure sequence.

After listening to these instructions and asking any questions about the procedure, the subjects were shown 4 of the slides once again. These 4 test slides were those taken from the 4 stimulus photographs used in the first experiment. Each slide was shown once for 5 min, followed by an interval of about 2 min until the next slide appeared. The order in which the 4 slides were shown corresponded to the order of the 4 Form B subscales (and the 4 fictitious names) within the booklets, so that a particular slide was always matched with the same name and list of activities across all subjects. This phase of the experiment lasted about $25 \mathrm{~min}$.

Finally, to check the effectiveness with which the perceived characteristics of the people appearing in the 4 test slides had been manipulated, the subjects were asked to think about how similar each of those individuals might be to themselves. The subjects were then instructed to write down the names of those 4 men, from most similar to least similar, on the backs of the pages containing the rating scales. A subsequent examination of these responses indicated that the similarity manipulation was indeed successful.

When the subjects had finished the experiment they were asked to make some guesses about the hypotheses being tested in the research. Five subjects, or about $8 \%$ of the sample, were able to identify correctly at least one of those hypotheses. The responses of these subjects were later found to be no different, however, from those generated by the rest of the sample. After describing their impressions of the experiment, the subjects were debriefed, allowed to ask questions, and thanked for their participation.

\section{Results}

Data analyses focused on the effects that sex and similarity had on the attractiveness and perceived familiarity of the people shown in the 4 test slides. Similarity was defined objectively in terms of the number of activity preferences that the subject shared with the people shown in the test slides, and not subjectively in terms of how similar the subjects believed those people were to themselves. There were thus 4 levels of similarity for each subject, depending on the number $(2,4,6$, or 8$)$ of 
activity preferences that he or she shared with the person shown in each of those slides. Interpersonal attraction was measured by the subjects' ratings of how much they would like the people in the test slides if they were actually to meet them. Perceived familiarity was measured by the subjects' ratings of how familiar those 4 individuals seemed to be. ${ }^{6}$

The effects of similarity on attraction and perceived familiarity are shown in Fig. 2. Once again, the data for men and women were quite similar and were therefore combined. The hypothesis seemed to be supported by the data. As the similarity of the people shown in the test slides increased, they were regarded as increasingly attractive and familiar by the subjects. Both of these effects were primarily linear in form; no significant curvilinear effects were observed in the data.

Again, a preliminary examination of the data indicated that the assumptions associated with the usual repeated measures analysis of variance techniques were not well met. Therefore, the same alternative analytical strategy adopted in the first experiment was used again. Two composite scores were created for each subject by weighting and then summing his or her separate responses. One score represented the linear effects of similarity on attraction, while the other score represented the linear effects of similarity on perceived familiarity. These composite scores provided information on the strength and direction of the linear trend in each dependent measure across levels of similarity.

Analyses of the composite scores revealed significant positive linear effects of similarity on both dependent measures. The average attraction score $(M=5.30)$ was significantly greater than zero, $t(63)=6.43, p$ $<.01$, as was the average score $(M=3.27)$ for perceived familiarity, $t(63)=3.51, p<.01$. The influence of similarity on the subjects' familiarity ratings was particularly interesting, since the subjects actually "encountered" each of the 4 test persons an equal number of times. That is, the actual familiarity of those 4 individuals was the same, yet their perceived familiarity varied directly with the number of activity preferences that they shared with the subjects.

Although these initial analyses supported the hypothesis, they failed to reveal why subjects felt more familiar with people who were similar to themselves. To explore the causal nature of the observed effects more closely, two regression analyses were again performed on the subjects' linear composite scores. In the first analysis, the subjects' perceived familiarity scores $(P F)$ were regressed on their attraction scores $(A)$. This

\footnotetext{
'Subjects' estimates of how often the faces appeared during the original exposure sequence were correlated highly with their familiarity ratings of those faces and showed the same basic pattern of results: The frequency estimates were wildly inaccurate, however, ranging from 0 to 40 exposures, and appeared to contain a good deal of error variance related to individual response styles. The familiarity ratings, which were known to be reliable and were also measured on the same type of scale as attraction, were therefore chosen as the primary measure of perceived familiarity.
} 


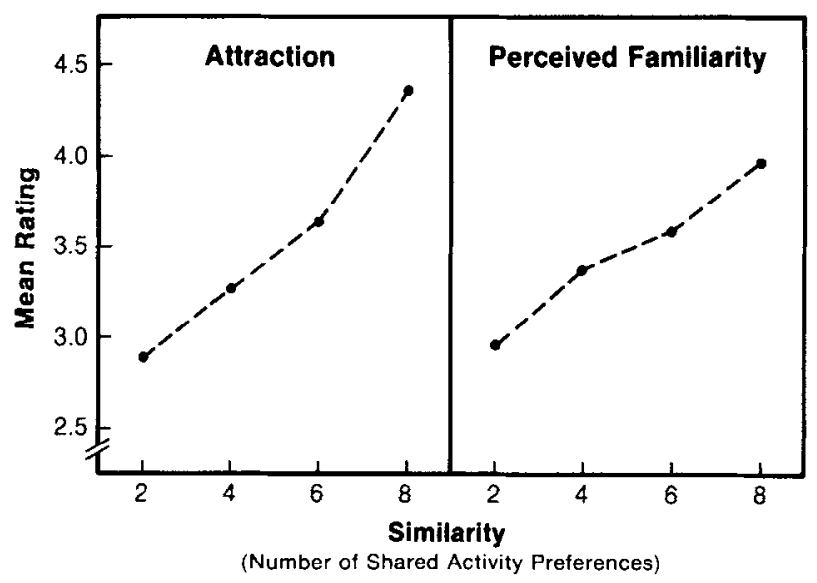

FIG. 2. Effects of similarity on perceived familiarity and attraction.

regression was significant, $F(1,62)=13.16, p<.01$, with an $R^{2}$ of .18 and a standard error of 6.82 . Once again, the regression equation generated by the analysis, $\hat{P F}=.76+.47 \mathrm{~A}$, provided information regarding the probable pattern of causal relations within the data. In particular, the additive constant from that equation estimated the strength and direction of any linear effects that similarity might have had on perceived familiarity had there been no linear effects of similarity on attraction $(A=0)$. Tests of the additive constant showed that it was not significantly larger than zero, $t(62)=.69, p>.05$, and was smaller, $t(62)=-2.28$, $p<.05$, than the observed mean perceived familiarity score $\left(b_{0}=.76\right.$ vs. $M=3.27) .^{7}$ In fact, the regression analysis indicated that removing all of the linear trends in attraction would have eliminated nearly threefourths of the average linear trend in perceived familiarity. All of this suggests that attraction was an essential mediator of the observed effects of similarity on perceived familiarity.

Although there was no evidence that similarity had any direct effects on perceived familiarity, a second regression analysis was also performed in which the subjects' attraction scores were regressed on their perceived familiarity scores. Naturally, the regression was unchanged $\left(R^{2}=.18\right)$, but had a new standard error of 6.04. The regression equation generated by this second analysis, $\hat{A}=4.09+.37 P F$, again provided information regarding the probable pattern of causal relations within the data. In this case, the additive constant from that equation indicated whether perceived familiarity mediated the effects of similarity on attraction. Tests of the additive constant revealed that it was still larger than zero, $t(62)$ $=4.96, p<.01$, but not significantly smaller, $t(62)=-1.47, p>.05$,

${ }^{7}$ Again, one could also test the hypothesis that the observed average perceived familiarity score was larger than the constant from the regression equation. This alternative test was also significant, $t(63)=2.69, p<.01$. 
than the original mean attraction score $\left(b_{0}=4.09\right.$ vs $\left.M=5.30\right)$. Thus, the evidence suggests that the observed effects of similarity on attraction would have changed very little had there been no corresponding effects of similarity on perceived familiarity.

\section{GENERAL DISCUSSION}

The results from these two experiments provided some new and interesting information about the potential role of exposure effects in person perception. In the first experiment, repeated exposure to other people led the subjects to alter both their attitudes and their beliefs about those individuals. As each stimulus person became more familiar to the subjects, he also elicited greater feelings of attraction from them. Similar attitudinal changes have already been observed in many other studies, but the first experiment also showed that mere exposure affected the subjects' beliefs about the similarity of the people that they saw. As each stimulus person became more familiar to the subjects, he also appeared to share more of their own preferences for various value-related activities. This latter effect, which has not yet been observed in any other research, suggests that familiarity may well influence our perceptions of other people in a variety of ways.

The second experiment explored the relationship between familiarity, similarity, and attraction from a somewhat different perspective. When the objective familiarity of a set of stimulus persons was held constant, subjects felt greater attraction for those individuals who were more similar to themselves. Once again, such findings are hardly noteworthy, as they have already been reported by many other investigators. However, similarity also had an effect on the subjects' beliefs about the familiarity of the people that they saw. Insofar as a particular individual was similar to the subjects, they also tended to believe that he was familiar to them. This suggests that there may actually be a reciprocal relationship between familiarity and similarity in which each factor enhances the other until some form of perceptual equilibrium has been attained.

These findings have several interesting theoretical implications. The data from both experiments indicated that attraction played an important role in mediating the observed relationship between familiarity and similarity. Two forms of evidence seemed to support this interpretation of the results. First, both data sets contained one independent and two dependent variables, all of which were correlated positively with one another. As Birnbaum and Mellers (1979) have demonstrated, the most parsimonious explanation for data sets of this sort involves a single mediating factor, which arises from the independent variable and is measured imperfectly (with uncorrelated errors) by the two dependent variables. Assuming that some such factor was indeed operating in both experiments, there is no way to determine exactly what its nature might have been. On the basis of the relevant research literature (e.g., Byrne, 
1969; Harrison, 1977), however, the most likely candidate is clearly interpersonal attraction.

A more direct form of evidence regarding the pattern of causal relations among familiarity, similarity, and attraction was provided by the regression analyses performed on each data set. In both experiments, the observed relationship between familiarity and similarity was reduced significantly or eliminated entirely when the effects of attraction were held constant. This suggests even more strongly that attraction was an important, if not essential, mediator of the relationship between familiarity and similarity. The subjects in the first experiment thus regarded familiar people as more similar to themselves primarily because those individuals were also more likeable. In the second experiment, people who were similar to the subjects were also more likeable, and that is what made them seem more familiar as well.

The diagram shown in Fig. 3 represents a general causal model, consistent with the data, of the apparent relationship between familiarity, similarity, and attraction. Several theoretical perspectives could be taken toward the various processes shown in the figure. On the whole, however, the model is consistent with Heider's (1958) views regarding the influence of structural balance on person perception. According to Heider, unit relations and sentiment relations often follow from one another. This certainly appeared to be true within these two data sets. Both experiments involved a manipulation of the strength of the objective unit relations (familiarity or similarity) between the subjects and a set of stimulus persons. Once these objective unit relations were established, they produced sentiment relations (interpersonal attraction) of corresponding strengths, which in turn led to the perception of new subjective unit relations (perceived similarity or perceived familiarity). Although it was not possible to measure any further changes in the subjects' attitudes or beliefs, such changes may well have occurred. Unit and sentiment relations may have continued to affect one another, in cycles of diminshing magnitude, until a state of structural balance was attained. Thus, familiarity may have led to greater attraction, which in turn produced an increase in perceived similarity. Perceived similarity may then have led to additional attraction, which in turn produced an increase in perceived familiarity, and so on.

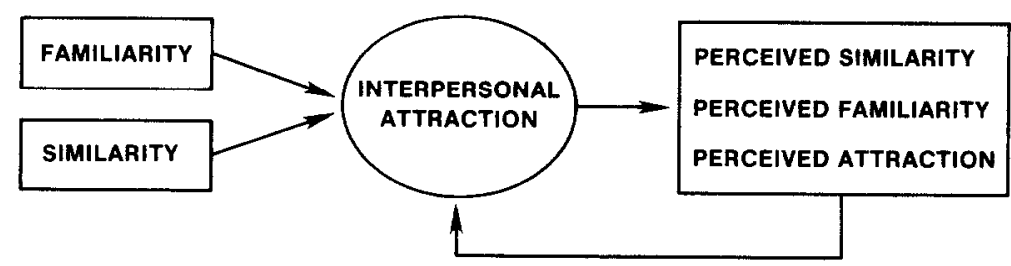

FIG. 3. Exposure effects in person perception: familiarity, similarity, and attraction. 
The apparent confluence of perceived familiarity, perceived similarity, and attraction in the data was particularly intriguing since it corresponds to the everyday experience of affinity. Affinity involves feelings of "closeness" to others, and thus includes elements of familiarity, similarity, and attraction. A number of psychologists have commented on this perceptual admixture. For example, Heider (1958) noted that "It is sometimes difficult to isolate the effects of dissimilarity from the effects of unfamiliarity ... Likewise, people who are similar to us are also familiar to us in some way . . . similarity and familiarity as well as their opposites seem to have parallel roles in cases of balance involving sentiments and unit relations" (p. 186). Titchener (1916) made a similar point when he observed that an encounter with a familiar person often produces "a glow of warmth, a feeling of intimacy, a feeling of sociable ease, of relaxation from the formal manner that you wear with strangers" (p. 178). The close relationship between familiarity, similarity, and attraction is also reflected in our language. The word "familiar," for instance, is derived from the Old French word for family. Aside from its usual meaning, familiarity thus connotes similarity in background as well. We also call familiar anyone with whom we share an especially friendly or intimate relationship. A contrasting example is provided by the word "alien," which can be traced back to an Old French word signifying strange origins. Alien can refer to someone who is new to us, or to a person who simply differs from us in some way. We also describe as alien anyone who is repulsive or distasteful. All of this suggests that affinity may be a common psychological phenomenon worthy of further research.

Clearly, the proposed model of the relationship between familiarity, similarity, and attraction will require additional elaboration and testing before it can be validated. In the meantime, however, the data that have already been collected seem to warrant at least two general conclusions. First, exposure effects play a much broader role in person perception than was suspected previously. Mere exposure to other people enhances their perceived similarity as well as their likeableness, and could conceivably affect many other social judgments that are related to interpersonal attraction. A second conclusion to be drawn from the data is that familiarity, similarity, and attraction are interdependent to some extent. The basis for that interdependence has yet to be determined. A balance model seems to account fairly well for the data that have been collected thus far, but further research will obviously be needed before the relationship between familarity, similarity, and attraction can be specified completely.

\section{REFERENCES}

Adams-Webber, J. The golden section and structure of self-concepts. Perceptual and Motor Skills, 1977, 45, 703-706. 
Arkin, R. M., \& Burger, J. M. Effects of unit relation tendencies on interpersonal attraction. Social Psychology Quarterly, 1980, 43, 380-391.

Backman, C. W., \& Secord, P. F. Liking, selective interaction, and misperception in congruent interpersonal relations. Sociometry, 1962, 25, 321-335.

Benjafield, J., \& Adams-Webber, J. Assimilative projection and construct balance in the repertory grid. British Journal of Psychology, 1975, 66, 169-173.

Bieri, J. Changes in interpersonal perceptions following social interaction. Journal of Abnormal and Social Psychology, 1953, 48, 61-66.

Birnbaum, M. H., \& Mellers, B. A. Stimulus recognition may mediate exposure effects. Journal of Personality and Social Psychology, 1979, 37, 391-394.

Blanchard, W. A. Assimilation and contrast in interpersonal prediction with control for the interaction of real similarity and differential accuracy. Journal of Personality and Social Psychology, 1966, 3, 567-573.

Brockner, J., \& Swap, W. C. Effects of repeated exposure and attitudinal similarity on self-disclosure and interpersonal attraction. Journal of Personality and Social Psychology, 1976, 33, 531-540.

Byrne, D. Attitudes and attraction. In L. Berkowitz (Ed.), Advances in experimental social psychology. New York: Academic Press, 1969.

Byrne, D., \& Blaylock, B. Similarity and assumed similarity of attitudes between husbands and wives. Journal of Abnormal and Social Psychology, 1963, 67, 636-640.

Byrne, D., \& Clore, G. L. A reinforcement model of evaluative responses. Personality: An International Journal, 1970, 1, 103-128.

Byrne, D., Gouaux, C., Griffitt, W., Lamberth, J., Murakawa, N., Prasad, M., Prasad, A., \& Ramirez, M. The ubiquitous relationship: Attitude similarity and attraction. Human Relations, 1971, 24, 201-207.

Byrne, D., \& Nelson, J. Attraction as a linear function of proportion of positive reinforcements. Journal of Personality and Social Psychology, 1965, 1, 659-663.

Cloyd, L. Effect of acquaintanceship on accuracy of person perception. Perceptual and Motor Skills, 1977, 44, 819-826.

Curry, T. J., \& Kenny, D. A. The effects of perceived and actual similarity in values and personality in the process of interpersonal attraction. Quality and Quantity, 1974, 8, $27-44$.

Davitz, J. Social peception and sociometric choice of children. Journal of Abnormal and Social Psychology, 1955, 50, 173-176.

Fiedler, F. E., Warrington, W. G., \& Blaisdell, F. J. Unconscious attitudes as correlates of sociometric choice in a social group. Journal of Abnormal and Social Psychology, 1952, 47, 790-796.

Gerard, H. B., Green, D., Hoyt, M., \& Conolley, E. S. Influence of affect on exposurefrequency estimates. Journal of Personality and Social Psychology, 1973, 28, 151-154.

Griffitt, W., Nelson, J., \& Littlepage, G. Old age and response to agreement-disagreement. Journal of Gerontology, 1972, 27, 269-274.

Hamm, N. H., Baum, M. R., \& Nikels, K. W. Effects of race and exposure on judgments of interpersonal favorability. Journal of Experimental Social Psychology, 1975, 11, $14-24$.

Harrison, A. A. Response competition, frequency, exploratory behavior and liking. Journal of Personality and Social Psychology, 1968, 9, 363-368.

Harrison, A. A. Mere exposure. In L. Berkowitz (Ed.), Advances in experimental social psychology. New York: Academic Press, 1977.

Harrison, A. A., Tutone, R. M., \& McFadgen, D. G. Effects of frequency of exposure of changing and unchanging stimulus pairs on affective ratings. Journal of Personality and Social Psychology, 1971, 20, 102-111.

Hays, W. L. Statistics. New York: Holt, Rinehart \& Winston, 1963.

Heider, F. The psychology of interpersonal relations. New York: Wilcy, 1958. 
Huynh, H., \& Feldt, L. S. Conditions under which mean square ratios in repeated measurements designs have exact F-distributions. Journal of the American Statistical Association, 1970, 65, 1582-1589.

Insko, C. A., \& Wilson, M. Interpersonal attraction as a function of social interaction. Journal of Personality and Social Psychology, 1977, 35, 903-911.

Matlin, M. W. Response competition as a mediating factor in the frequency-affect relationship. Journal of Personality and Social Psychology, 1970, 16, 536-552.

Matlin, M. W., \& Stang, D. J. The Pollyanna principle: Selectivity in language, memory, and thought. Cambridge, Mass.: Schenkman, 1978.

McLaughlin, B. Similarity, recall, and appraisal of others. Journal of Personality, 1970 , 38, 106-116.

McLaughlin, B. Effects of similarity and likeableness on attraction and recall. Journal of Personality and Social Psychology, 1971, 20, 65-69.

Messé, L. A., \& Sivacek, J. M. Prediction of others' responses in a mixed-motive game: Self-justification or false consensus? Journal of Personality and Social Psychology, 1979, 37, 602-607.

Moss, M. K., Byrne, D., Baskett, G. D., \& Sachs, D. H. Informational versus affective determinants of interpersonal attraction. Journal of Social Psychology, 1975, 95, 39-53.

Precker, J. A. The automorphic process in the attribution of values. Journal of Personality, 1953, 21, 356-363.

Rosenbaum, M. E. Social perception and the motivational structure of interpersonal relations. Journal of Abnormal and Social Psychology, 1959, 59, 130-133.

Ross, L., Greene, D., \& House, P. The false consensus phenomenon: An attributional bias in self perception and social perception processes. Journal of Experimental Social Psychology, 1977, 13, 279-301.

Saegert, S., Swap, W. C., \& Zajonc, R. B. Exposure, context, and interpersonal attraction. Journal of Personality and Social Psychology, 1973, 25, 234-242.

Shorr, J. The development of a test to measure the intensity of values. Journal of Educational Psychology, 1953, 44, 266-274.

Snyder, M. Seek and ye shall find: Testing hypotheses about other people. In E. T. Higgins, C. P. Herman, \& M. P. Zanna (Eds.), Social cognition: The Ontario symposium on personality and social psychology. Hillsdale, N.J.: Erlbaum, 1981.

Swap, W. Interpersonal attraction and repeated exposure to rewarders and punishers. Personality and Social Psychology Bulletin, 1977, 3, 248-251.

Taylor, S. E., \& Crocker, J. Schematic bases of social information processing. In E. T. Higgins, C. P. Hermann, \& M. P. Zanna (Eds.), The Ontario Symposium on Personality and Social Psychology. Hillsdale, N.J.: Erlbaum, 1981.

Titchener, E. B. A beginner's psychology. New York: Macmillan, 1916.

Wilson, W., \& Nakajo, H. Preference for photographs as a function of frequency of presentation. Psychonomic Science, 1965, 3, 577-578.

Wyer, R. S., \& Srull, T. K. The processing of social stimulus information: A conceptual integration. In R. Hastie, T. M. Ostrom, E. B. Ebbesen, R. S. Wyer, D. L. Hamilton, \& D. E. Carlston (Eds.), Person memory: The cognitive basis of social perception. Hillsdale, N.J.: Erlbaum, 1980.

Zajonc, R. B., Markus, H., \& Wilson, W. R. Exposure effects and associative learning. Journal of Experimental Social Psychology, 1974, 10, 248-263.

\section{REFERENCE NOTES}

1. Stang, D. J. An analysis of the effects of political campaigning. Paper presented at the meeting of the Southern Socicty for Philosophy and Psychology, Tampa, April, 1974.

2. Diamond, N. C., \& Miller, D. Effect of familiarization on ratings of photographs of 
old people. Paper presented at the meeting of the American Psychological Association, New York, September, 1979.

3. Stang, D. J. Influence of frequency and affect on exposure frequency estimates. Paper presented at the meeting of the Eastern Psychological Association, Philadelphia, May, 1974. 